\title{
Preliminary Study Characterizing the Use of Sitagliptin for Glycemic Control in Healthy Beagle Dogs with Normal Gluco-Homeostasis
}

\author{
Hitomi ODA ${ }^{1)}$, Akihiro MORI ${ }^{1) *}$, Peter LEE ${ }^{2)}$, Kaori SAEKI ${ }^{1)}$, Toshiro ARAI $^{2)}$ and Toshinori SAKO ${ }^{1)}$ \\ ${ }^{1)}$ School of Veterinary Nursing and Technology, Faculty of Veterinary Science, Nippon Veterinary and Life Science University, 1-7-1 \\ Kyonancho, Musashino, Tokyo 180-8602, Japan \\ ${ }^{2}$ School of Veterinary Medicine, Faculty of Veterinary Science, Nippon Veterinary and Life Science University, 1-7-1 Kyonancho, \\ Musashino, Tokyo 180-8602, Japan
}

(Received 26 November 2013/Accepted 27 May 2014/Published online in J-STAGE 16 June 2014)

ABSTRACT. Sitagliptin is a dipeptidyl peptidase-4 inhibitor aimed at treating Type 2 diabetes mellitus (T2DM) and T1DM, by increasing blood levels of Glucagon-like peptide 1 (GLP-1) and insulin. The objective of this preliminary study is to characterize Sitagliptin's ability for glycemic control, in healthy dogs under an oral glucose tolerance test (OGTT) environment. Overall, Sitagliptin did not result in any significant changes to temporal glucose and insulin concentrations. However, a $\sim 55 \%$ increase in median total GLP-1 AUC $0-120$ min was observed, as compared to baseline control in healthy dogs $(n=5)$, thus indicating a similar mode of action of Sitagliptin between healthy dogs and humans. Future studies to validate the use of Sitagliptin with dogs suffering from insulin independent diabetes are warranted. KEY WORDS: canine, GIP, GLP-1, glucose, insulin, Sitagliptin

doi: 10.1292/jvms.13-0590; J. Vet. Med. Sci. 76(10): 1383-1387, 2014

To date, only glucose-dependent insulinotropic polypeptide (GIP) and glucagon-like peptide-1 (GLP-1) fulfill the definition of an incretin hormone in humans [10]. These hormones are released by gut endocrine cells in response to a meal and regulate blood glucose levels by stimulating glucose-dependent insulin secretion. Furthermore, these two peptides potentiate glucose- stimulated insulin secretion in an additive manner, likely contributing and accounting for the majority of the "incretin effect" in humans [2]. The concept that oral glucose administration promotes a much greater increase in plasma insulin levels, as compared to the same amount of glucose given intravenously [28] underlies the "incretin effect" [30], which is estimated to account for approximately $50-70 \%$ of the total insulin secreted following oral glucose administration.

As such, incretins have potential therapeutic use as antihyperglycemic agents, receiving much attention as a potential new form of treatment for diabetes, especially against Type 2 diabetes mellitus (T2DM) originally, and more recently, T1DM $[1,13,15,19,25]$. However, the therapeutic potential of endogenous GLP-1 and GIP is limited, because of rapid inactivation by dipeptidyl peptidase-4 (DPP-4) $[8,35]$. Enhanced incretin preparations, such as DPP-4 inhibitors and DPP-4 resistant GLP-1 analogs, have emerged as new classes of antihyperglycemic agents [11, 29], with clinical data in humans demonstrating that incretin preparations can

*Correspondence to: Mori, A., Department of Veterinary Nursing and Technology, Nippon Veterinary and Life Science University 1-7-1 Kyonancho, Musashino, Tokyo 180-8602, Japan. e-mail: amori@nvlu.ac.jp

(C2014 The Japanese Society of Veterinary Science

This is an open-access article distributed under the terms of the Creative Commons Attribution Non-Commercial No Derivatives (by-nc-nd) License $<$ http://creativecommons.org/licenses/by-nc-nd/3.0/>. improve glycemic control by stimulating insulin secretion in diabetic patients $[4,5,12,31]$.

DPP-4 inhibitors or gliptins are a class of oral hypoglycemic compounds that block DPP-4. The first agent of the class is Sitagliptin, developed and marketed by Merck Pharmaceuticals, which received approval from the U.S. Food and Drug Administration (USFDA) in 2006. Sitagliptin works to increase and stabilize active form incretin levels, by competitively inhibiting DPP-4, which normally breaks down GLP-1 and GIP [19]. By preventing GLP-1 and GIP inactivation, both incretins are able to increase insulin secretion, decrease gastric acid secretion and decrease blood glucose levels. Recently, extending the use of DPP-4 inhibitors to T1DM has been suggested. Recent studies in human patients suffering from T1DM demonstrated that Sitagliptin significantly improved overall glucose control, including postprandial and 24-hr glucose control, in adult patients with T1DM, while significantly reducing prandial insulin requirements $[12,16,17,25]$

Surprisingly, the pharmacokinetics, metabolism and excretion of Sitagliptin have been previously evaluated in beagle dogs $[3,24]$, however, the use of Sitagliptin for glycemic control in dogs has yet to be documented and evaluated. As such, the main objective of this preliminary preclinical study was to assess and determine the effect of Sitagliptin on glucose metabolism in healthy dogs by monitoring serum glucose, insulin and GLP-1 levels, during oral glucose tolerance test (OGTT) for potential clinical use treating diabetes in dogs. The incretin effect exists in dogs [22, 32], so the mechanism of Sitaglitpin action would mirror that in humans. Because the majority of, if not all, clinical diabetes cases in dogs is insulin-dependent (T1DM), withT2DM cases being extremely rare [6], logic dictates that the effectiveness of Sitagliptin in dogs would be severely hampered in cases of insulin deficiency, since Sitagliptin's main mechanism of ac- 
tion is increased insulin secretion via incretin stabilization. However, our laboratory previously demonstrated that GLP1 analogs show potent glucose-lowering action in healthy and T1DM dogs [32], similarly in T2DM suffering humans [26]. Therefore, the incretin pathway is not exclusively insulin dependent regarding its glucose lowering ability, and as such, in spite of the ineffectiveness of Sitagliptin's pro-insulin secretion characteristic in dogs, it may be able to lower blood glucose via alternate mechanisms.

Throughout the study, the same five healthy beagles (2 castrated males and 3 spayed females, 6.16-13.04 kg BW, 3-5 years old), were maintained in our laboratory for research purposes and served as healthy controls. All dogs were fed on a commercial diet (Select Protein, Royal Canin Japon, Tokyo, Japan) twice a day ( 8 am and $8 \mathrm{pm}$ ), and the caloric intake was set at $1 / 2 \times 1.6 \times \mathrm{RER}\left(\mathrm{BW}^{0.75} \times 70\right)$ for each feeding period, whereby RER means the resting energy requirement and BW means body weight for dogs [9]. Approval for this work has been given by the Nippon Veterinary and Life Science University Animal Research Committee.

Oral administration of glucose solution $(1.0 \mathrm{~g} / \mathrm{kg}$, FUSO glucose 50\%PL, FUSO Pharmaceutical Industries, Ltd., Tokyo, Japan) lasted for over $30 \mathrm{sec}$, and the dose of administered glucose solution was referenced in a previous study [21]. This was carried out in replicate using the same five dogs twice with a 2-week washout period.

In order to determine Sitagliptin's effect, Sitagliptin (JANUVIA $^{\circledR}$; MSD K.K., Yokohama, Japan) was initially orally administered to 5 healthy dogs at $1.0 \mathrm{mg} / \mathrm{kg}$ at $8: 00$ am, following a $12 \mathrm{hr}$ overnight fasting period. This was a referenced clinical dose used with T2DM patients in Japan [23] and was administered on a daily basis for a period of 7 days. OGTT was performed on the last day of Sitagliptin administration with Sitagliptin being administered $1 \mathrm{hr}$ prior to performing the OGTT [27].

For all procedures (OGTT, OGTT + Sitagliptin), blood was obtained from the jugular vein of each dog immediately prior to (0) and 5, 10, 15, 20,30, 45, 60, 90 and $120 \mathrm{~min}$ after glucose administration [32]. Serum glucose, insulin and plasma GLP-1 concentrations were subsequently also measured over a $2 \mathrm{hr}$ period post initial glucose administration.

Blood samples for glucose and insulin were collected into polypropylene tubes and allowed to clot at room temperature for $15 \mathrm{~min}$. Immediately after clotting, blood samples were centrifuged at $1,700 \mathrm{~g}$ for $10 \mathrm{~min}$ at $4^{\circ} \mathrm{C}$ to obtain serum. Blood samples for GLP-1 assaying were collected into icecooled Vacutainer ${ }^{\circledR}$ EDTA-plasma tubes. Immediately after collection, an appropriate amount (10 $\mu l$ of DPP-4 inhibitor per $\mathrm{m} l$ of blood) of DPP-4 inhibitor reagent solution (DPPIV Inhibitor; Millipore Headquarters, Billerica, MA, U.S.A.) was added, according to the manufacturer's instructions. Samples were immediately centrifuged at $1,000 \mathrm{~g}$ for 10 min at $4^{\circ} \mathrm{C}$ to obtain plasma. The serum and plasma samples were immediately stored at $-80^{\circ} \mathrm{C}$ until further use.

Serum samples were used to measure glucose and insulin using a Wako2 Glucose test commercial kit (Wako Pure Chemical Industries, Tokyo, Japan) and a Morinaga Dog Insulin commercial ELISA Kit (Morinaga Institute of
Biological Science, Yokohama, Japan), respectively. Alternatively, plasma samples were used to determine GLP-1 concentration, which was measured using a commercial Glucagon-Like Peptide-1 (Active) 96-Well Plate ELISA Kit for humans (Millipore Headquarters) according to the manufacturer's protocol. This GLP-1 ELISA kit was previously validated for use in dogs [33] with intra- and interassay variability of $4.5 \%$ and $12.9 \%$, respectively, for canine GLP-1 concentrations.

Data are presented as median [min, max]. Total area under the curve during 0-120 min $\left(\mathrm{AUC}_{0-120 \mathrm{~min}}\right)$ for glucose, insulin and GLP-1 was calculated by the trapezoidal rule. Statistical significance was determined by Mann-Whitney $U$-test. Statistical significance was set at $P<0.05$. All tests were conducted using Sigmaplot analysis software (Sigmaplot 11.0, Build 11.0.077; Systat Software Inc., San Jose, CA, U.S.A.).

With respect to glucose and insulin concentrations, Sitagliptin exhibited no significant effects, rendering similar temporal patterns as baseline control, respectively (Fig. 1a and $1 \mathrm{~b}$ ). This was reflected by similar values in total glucose

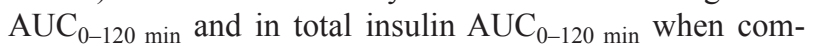
pared to baseline control $(13,468[10,913,16,188]$ versus $13,462[11,423,16,168]$ and $76.3[54.6,84.22]$ versus 70.0 $[44.2,95.0]$; respectively). This was to be expected, since the OGTT was applied in healthy animals with normal glucose homeostasis ability and which were fully capable of producing insulin and insulin secretion. Sitagliptin's ability to increase or enhance secretion of insulin appears to be negligible and unmeasurable in healthy animals due to normal glucose homeostasis. However, the lack of any change in glucose concentration is interesting, since a previous study by our laboratory, involving Liraglutide, a long-acting acylated human GLP-1 receptor agonist, with a 97\% amino acid sequence identity to endogenous human GLP-1, demonstrated a reduction in glucose concentration without any accompanying changes in insulin levels in an OGTT with healthy dogs with normal gluco-homeostasis [32].

We speculate that in the Liraglutide study, the reduction in glucose concentration was most likely due to the action of GLP-1 mediated delaying of gastric emptying and suppression of prandial glucagon secretion [14, 34]. However, Sitagliptin's action is not exclusive to GLP-1 only [19] and works to competitively inhibit DPP-4, which inactivates incretin enzymes, such as GIP and GLP-1. By preventing GLP-1 inactivation, Sitagliptin is able to potentiate the secretion of insulin and suppress the release of glucagon by the pancreas. However, GIP has been shown to possess glucagonotropic effects in human subjects, and recent findings implicate GIP as a "diabetogenic" hormone [7]. GIP is known to stimulate the secretion of both insulin and glucagon which might negate the glucagon suppressive effect of GLP-1 [2], which may help to explain the lack of any changes to glucose level with Sitagliptin as compared to a reduction with Liraglutide. Therefore, under a clinical setting in a diabetic dog, there may be a strong possibility for a lack of any changes observed with glucose concentration, after administration of Sitagliptin, due to unchanged glucagon concentrations. 

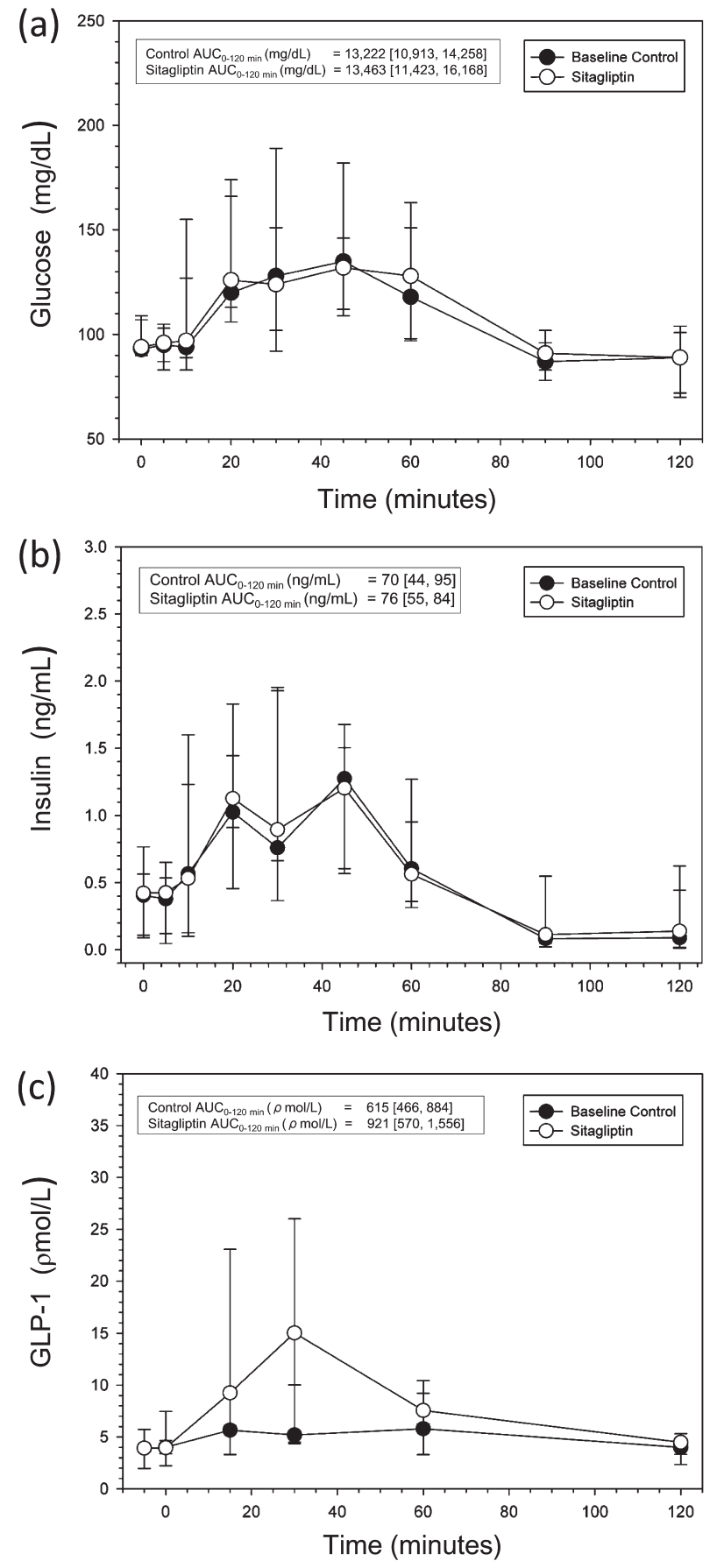

Fig. 1. Effect of Sitagliptin on glycemic control in healthy dogs $(n=5)$. Determination of temporal changes in serum (a) glucose, (b), insulin and (c) GLP-1 concentration with baseline control values. Total area under the curve $(0-12 \mathrm{hr})$ is indicated as insets within each figure. Results are expressed as median [min, max].

In human T2DM subjects receiving Sitagliptin, a significant increase in intact GLP-1 and GIP concentrations with no corresponding changes to glucagon concentration was observed after 1 week of treatment [1], which would support our possible speculation. Interestingly, however, although Sitagliptin use in human T1DM patients did not alter postprandial glucagon AUC [15], overall glucose control was improved, including postprandial and 24-hr glucose control [12], which suggests that although GIP may negate the glucagon suppressive effect of GLP-1 [2], GLP-1 does have other mechanisms to reduce post-prandial hyperglycemia, such as delaying gastric emptying [12, 30] for example, which would prevent any large influx in glucose concentration and aid in alleviating the need for a sudden large amount of insulin secretion, which is lacking in T1DM [18]. As such, future experiments with Sitagliptin and insulin dependent diabetic dogs are needed to shed light on whether Sitagliptin can alter glucose concentration under a clinical setting or not. In addition, the relationship between Sitagliptin and plasma glucagon and/or GIP concentration should be further studied and pursued in future studies. Unfortunately, due to the unavailability of a commercially available canine glucagon or GIP ELISA kit, measuring plasma glucagon or GIP concentrations will prove to be a challenge in any future study involving Sitaliptin in T1DM dogs.

Regarding GLP-1 concentration, Sitagliptin appeared to have a biological effect, resulting in greater median levels of GLP-1 observed at the 15 and 30 min time points of the OGTT as compared to baseline control (Fig. 1c). This was expected due to the nature of the mechanism of action of Sitagliptin, which prolongs the active state of GLP-1. However, neither increase of median GLP-1 levels at the two aforementioned time points was considered to be statistically significant when compared to baseline control (Mann Whitney $U$-test, $P=0.690)$. As a consequence, although the median value for Sitagliptin total GLP-1 $\mathrm{AUC}_{0-120 \text { min }}$ was $\sim 55 \%$ greater than baseline control $(921.2$ [570.5, 1,556.4] versus $615.1[465.5,884.3])$, this was not considered statistically significant (Mann Whitney $U$-test, $P=0.151$ ). We speculate that this result would be considered statistically significant with a larger cohort of animals perhaps, and this negative result is mainly attributed to the low power of our sample $(n=5)$. In addition, the dosage of Sitagliptin required to demonstrate significance with healthy animals may differ from the amount used in the study, since the amount used was a referenced clinical dose used with human T2DM patients in Japan [23]. Moreover, the greater median levels of GLP-1 observed were not accompanied by any changes observed with plasma glucose concentration. This appears to be in accordance with the results from studies focusing on the pharmacokinetics and pharmacodynamics of Sitagliptin in healthy humans, in which Sitagliptin increased the postprandial rise in active glucagon-like peptide 1 concentrations without causing hypoglycemia in normoglycemic healthy male volunteers [4, 20]

In conclusion, Sitagliptide's ability to act as a DPP-4 inhibitor appears to increase plasma GLP-1 concentration, while leaving blood glucose and insulin levels unchanged in healthy dogs, which is similar with healthy humans. Further testing with different doses in healthy dogs should reveal more information about the correct dose to use with insulin dependent diabetes mellitus (IDDM) dogs. In addition, 
future studies involving the administration of Sitagliptin in dogs with insulin secretion impairment or IDDM will offer further validation for the use of Sitagliptin, as a hypoglycemic agent, in dogs.

\section{REFERENCES}

1. Aaboe, K., Knop, F. K., Vilsbøll, T., Deacon, C. F., Holst, J. J., Madsbad, S. and Krarup, T. 2010. Twelve weeks treatment with the DPP-4 inhibitor, sitagliptin, prevents degradation of peptide YY and improves glucose and non-glucose induced insulin secretion in patients with type 2 diabetes mellitus. Diabetes Obes. Metab. 12: 323-333. [Medline] [CrossRef]

2. Baggio, L. L. and Drucker, D. J. 2007. Biology of incretins: GLP-1 and GIP. Gastroenterology 132: 2131-2157. [Medline] [CrossRef]

3. Beconi, M. G., Reed, J. R., Teffera, Y., Xia, Y. Q., Kochansky, C. J., Liu, D. Q., Xu, S., Elmore, C. S., Ciccotto, S., Hora, D. F., Stearns, R. A. and Vincent, S. H. 2007. Disposition of the dipeptidyl peptidase 4 inhibitor sitagliptin in rats and dogs. Drug Metab. Dispos. 35: 525-532. [Medline] [CrossRef]

4. Bergman, A. J., Stevens, C., Zhou, Y., Yi, B., Laethem, M., De Smet, M., Snyder, K., Hilliard, D., Tanaka, W., Zeng, W., Tanen, M., Wang, A. Q., Chen, L., Winchell, G., Davies, M. J., Ramael, S., Wagner, J. A. and Herman, G. A. 2006. Pharmacokinetic and pharmacodynamic properties of multiple oral doses of sitagliptin, a dipeptidyl peptidase-IV inhibitor: a double-blind, randomized, placebo-controlled study in healthy male volunteers. Clin. Ther. 28: 55-72. [Medline] [CrossRef]

5. Bode, B. W., Testa, M. A., Magwire, M., Hale, P. M., Hammer, M., Blonde, L., Garber A., LEAD-3 Study Group 2010. Patientreported outcomes following treatment with the human GLP-1 analogue liraglutide or glimepiride in monotherapy: results from a randomized controlled trial in patients with type 2 diabetes. Diabetes Obes. Metab. 12: 604-612. [Medline] [CrossRef]

6. Catchpole, B., Ristic, J. M., Fleeman, L. M. and Davison, L. J. 2005. Canine diabetes mellitus: can old dogs teach us new tricks? Diabetologia 48: 1948-1956. [Medline] [CrossRef]

7. Chia, C. W., Carlson, O. D., Kim, W., Shin, Y. K., Charles, C. P., Kim, H. S., Melvin, D. L. and Egan, J. M. 2009. Exogenous glucose-dependent insulinotropic polypeptide worsens post prandial hyperglycemia in type 2 diabetes. Diabetes $\mathbf{5 8}$ : 1342-1349. [Medline] [CrossRef]

8. Deacon, C. F., Nauck, M. A., Toft-Nielsen, M., Pridal, L., Willms, B. and Holst, J. J. 1995. Both subcutaneously and intravenously administered glucagon-like peptide I are rapidly degraded from the NH2-terminus in type II diabetic patients and in healthy subjects. Diabetes 44: 1126-1131. [Medline] [CrossRef]

9. Debraekeloer, J., Gross, K. and Zicker, S. 2000. Chapter 9. Normal dogs. pp.213-260. In: Small Animal Clinical Nutrition, 4th ed. (Hand, M. M., Thatcher, C. D., Remillard, R. L., Roudebush, P. and Novotny, B. J. eds.), Mark Morris Institute, Topeka.

10. Drucker, D. J. 2007. The role of gut hormones in glucose homeostasis. J. Clin. Invest. 117: 24-32. [Medline] [CrossRef]

11. Drucker, D. J. and Nauck, M. A. 2006. The incretin system: glucagon-like peptide- 1 receptor agonists and dipeptidyl peptidase-4 inhibitors in type 2 diabetes. Lancet 368: 1696-1705. [Medline] [CrossRef]

12. Ellis, S. L., Moser, E. G., Snell-Bergeon, J. K., Rodionova, A. S., Hazenfield, R. M. and Garg, S. K. 2011. Effect of sitagliptin on glucose control in adult patients with Type 1 diabetes: a pilot, double-blind, randomized, crossover trial. Diabet. Med. 28: 1176-1181. [Medline] [CrossRef]
13. Fakhoury, W. K., Lereun, C. and Wright, D. 2010. A meta-analysis of placebo- controlled clinical trials assessing the efficacy and safety of incretin-based medications in patients with type 2 diabetes. Pharmacology 86: 44-57. [Medline] [CrossRef]

14. Garber, A. J. 2012. Novel GLP-1 receptor agonists for diabetes. Expert Opin. Investig. Drugs 21: 45-57. [Medline] [CrossRef]

15. Garg, S. K., Moser, E. G., Bode, B. W., Klaff, L. J., Hiatt, W. R., Beatson, C. and Snell-Bergeon, J. K. 2013. Effect of sitagliptin on post-prandial glucagon and GLP-1 levels in patients with type 1 diabetes: investigator-initiated, double-blind, randomized, placebo-controlled trial. Endocr. Pract. 19: 19-28. [Medline] [CrossRef]

16. Giampietro, O., Giampietro, C., Bartola, L. D., Masoni, M. C. and Matteucci, E. 2013. Sitagliptin as add-on therapy in insulin deficiency: biomarkers of therapeutic efficacy respond differently in type 1 and type 2 diabetes. Drug Des. Devel. Ther. 7: 99-104. [Medline]

17. Hari Kumar, K. V., Shaikh, A. and Prusty, P. 2013. Addition of exenatide or sitagliptin to insulin in new onset type 1 diabetes: a randomized, open label study. Diabetes Res. Clin. Pract. 100: e55-e58. [Medline] [CrossRef]

18. Harrison, L. B., Mora, P. F., Clark, G. O. and Lingvay, I. 2013. Type 1 diabetes treatment beyond insulin: role of GLP-1 analogs. J. Investig. Med. 61: 40-44. [Medline]

19. Herman, G. A., Bergman, A., Stevens, C., Kotey, P., Yi, B., Zhao, P., Dietrich, B., Golor, G., Schrodter, A., Keymeulen, B., Lasseter, K. C., Kipnes, M. S., Snyder, K., Hilliard, D., Tanen, M., Cilissen, C., de Smet, M., de Lepeleire, I., Van Dyck, K., Wang, A. Q., Zeng, W., Davies, M. J., Tanaka, W., Holst, J. J., Deacon, C. F., Gottesdiener, K. M. and Wagner, J. A. 2006. Effect of single oral doses of sitagliptin, a dipeptidyl peptidase-4 inhibitor, on incretin and plasma glucose levels after an oral glucose tolerance test in patients with type 2 diabetes. J. Clin. Endocrinol. Metab. 91: 4612-4619. [Medline] [CrossRef]

20. Herman, G. A., Stevens, C., Van Dyck, K., Bergman, A., Yi, B., De Smet, M., Snyder, K., Hilliard, D., Tanen, M., Tanaka, W., Wang, A. Q., Zeng, W., Musson, D., Winchell, G., Davies, M. J., Ramael, S., Gottesdiener, K. M. and Wagner, J. A. 2005. Pharmacokinetics and pharmacodynamics of sitagliptin, an inhibitor of dipeptidyl peptidase IV, in healthy subjects: results from two randomized, double-blind, placebo-controlled studies with single oral doses. Clin. Pharmacol. Ther. 78: 675-688. [Medline] [CrossRef]

21. Hillaire-Buys, D., Bertrand, G., Chapal, J., Puech, R., Ribes, G. and Loubatières-Mariani, M. M. 1993. Stimulation of insulin secretion and improvement of glucose tolerance in rat and dog by the P2y-purinoceptor agonist, adenosine-5'-O-(2thiodiphosphate). Br. J. Pharmacol. 109: 183-187. [Medline] [CrossRef]

22. Ionut, V., Liberty, I. F., Hucking, K., Lottati, M., Stefanovski, D., Zheng, D. and Bergman, R. N. 2006. Exogenously imposed postprandial-like rises in systemic glucose and GLP-1 do not produce an incretin effect, suggesting an indirect mechanism of GLP-1 action. Am. J. Physiol. Endocrinol. Metab. 291: E779E785. [Medline] [CrossRef]

23. Iwamoto, Y., Tajima, N., Kadowaki, T., Nonaka, K., Taniguchi, T., Nishii, M., Arjona Ferreira, J. C. and Amatruda, J. M. 2010. Efficacy and safety of sitagliptin monotherapy compared with voglibose in Japanese patients with type 2 diabetes: a randomized, double-blind trial. Diabetes Obes. Metab. 12: 613-622. [Medline] [CrossRef]

24. Kim, D., Wang, L., Beconi, M., Eiermann, G. J., Fisher, M. H., He, H., Hickey, G. J., Kowalchick, J. E., Leiting, B., Lyons, K., 
Marsilio, F., McCann, M. E., Patel, R. A., Petrov, A., Scapin, G., Patel, S. B., Roy, R. S., Wu, J. K., Wyvratt, M. J., Zhang, B. B., Zhu, L., Thornberry, N. A. and Weber, A. E. 2005. (2R)4-oxo-4-[3-(trifluoromethyl)-5,6-dihydro[1,2,4]triazolo[4,3-a] pyrazin-7(8H)- yl]-1-(2,4,5-trifluorophenyl)butan-2-amine: a potent, orally active ipeptidyl peptidase IV inhibitor for the treatment of type 2 diabetes. J. Med. Chem. 48: 141-151. [Medline] [CrossRef]

25. Kutoh, E. 2011. Sitagliptin is effective and safe as add-on to insulin in patients with absolute insulin deficiency: a case series. J. Med. Case Rep. 5: 117. [Medline] [CrossRef]

26. Lee, W. C., Dekoven, M., Bouchard, J., Massoudi, M. and Langer, J. 2014. Improved real-world glycaemic outcomes with liraglutide versus other incretin-based therapies in type 2 diabetes. Diabetes Obes. Metab. doi: 10.1111/dom.12285. [Epub ahead of print]

27. Luo, J., Nguyen, K., Chen, M., Tran, T., Hao, J., Tian, B., Rulifson, I. C., Zhang, Y., Tian, L., Zhang, Y., Lopez, E., Lin, D. C., Wang, Y., Ma, Z., Houze, J. and Guo, Z. 2013. Evaluating insulin secretagogues in a humanized mouse model with functional human islets. Metabolism 62: 90-99. [Medline] [CrossRef]

28. McIntyre, N., Holdsworth, C. D. and Turner, D. S. 1965. Intestinal factors in the control of insulin secretion. J. Clin. Endocrinol. Metab. 25: 1317-1324. [Medline] [CrossRef]

29. Mest, H. J. and Mentlein, R. 2005. Dipeptidyl peptidase inhibitors as new drugs for the treatment of type 2 diabetes. Diabetologia 48: 616-620. [Medline] [CrossRef]

30. Nauck, M. A., Homberger, E., Siegel, E. G., Allen, R. C., Ea- ton, R. P., Ebert, R. and Creutzfeldt, W. 1986. Incretin effects of increasing glucose loads in man calculated from venous insulin and C-peptide responses. J. Clin. Endocrinol. Metab. 63: 492-498. [Medline] [CrossRef]

31. Nonaka, K., Kakikawa, T., Sato, A., Okuyama, K., Fujimoto, G., Kato, N., Suzuki, H., Hirayama, Y., Ahmed, T., Davies, M. J. and Stein, P. P. 2008. Efficacy and safety of sitagliptin monotherapy in Japanese patients with type 2 diabetes. Diabetes Res. Clin. Pract. 79: 291-298. [Medline] [CrossRef]

32. Oda, H., Mori, A., Lee, P., Saeki, K., Ishioka, K., Arai, T. and Sako, T. 2013. Characterization of the use of liraglutide for glycemic control in healthy and Type 1 diabetes mellitus suffering dogs. Res. Vet. Sci. 95: 381-388. [Medline] [CrossRef]

33. Pridal, L., Ingwersen, S. H., Larsen, F. S., Holst, J. J., Adelhorst, K. and Kirk, O. 1995. Comparison of sandwich enzyme-linked immunoadsorbent assay and radioimmunoassay for determination of exogenous glucagon-like peptide-1(7-36) amide in plasma. J. Pharm. Biomed. Anal. 13: 841-850. [Medline] [CrossRef]

34. Vilsbøll, T. and Garber, A. J. 2012. Non-glycaemic effects mediated via GLP-1 receptor agonists and the potential for exploiting these for therapeutic benefit: focus on liraglutide. Diabetes Obes. Metab. 14: 41-49. [Medline] [CrossRef]

35. Vilsbøll, T., Agersø, H., Krarup, T. and Holst, J. J. 2003. Similar elimination rates of glucagon-like peptide-1 in obese type 2 diabetic patients and healthy subjects. J. Clin. Endocrinol. Metab. 88: 220-224. [Medline] [CrossRef] 